\title{
Peran Teknologi Informasi Untuk Peningkatan Kemampuan Siswa SMA dan SMK Dalam Menghadapi Perkembangan Era Digital
}

\author{
Febri Liantoni ${ }^{1}$, Septiyawan Rosetya ${ }^{2}$, Rahmi Rizkiana ${ }^{3}$, \\ Farida $^{4}$, Luky Agus Hermanto 5 \\ 1,2,3,4,5 Teknik Informatika, Fakultas Teknologi Informasi, Institut Teknologi Adhi Tama Surabaya \\ febri.liantoni@itats.ac.id
}

\begin{abstract}
ABSTRAK
Pada era digital peran teknologi informasi sangat diperlukan untuk menghadapai persaingan ditengah masyarakat. Teknologi informasi dan komunikasi merupakan elemen yang penting dalam memberikan andil besar terhadap perubahan - perubahan yang mendasar pada struktur operasi dan manajemen organisasi, pendidikan, trasportasi, kesehatan dan penelitian. Dengan dilakukannya peningkata kemampuan dan ketrampilan siswa SMA dan SMK diharapakan siswa sekolah dapat menghadapi perkembangan era digital dengan lebih siap. Pelatihan dilakukan dengan cara mengundang para alumni teknik informatika ITATS untuk memberikan penjelasan dan peran teknologi informasi di dunia kerja. Selain itu siwa juga diberikan pelatihan pembuatan game android, pelatihan pengenalan Matlab untuk komputasi algoritma dan pelatihan pengenalan jaringan dengan simulasi packet tracer. Para siswa sekolah diberikan informasi prosedur dalam menghadapi perkembangan era digital didunia kerja. Hasil pelatihan ini memperoleh tingkat kepuasan yang tinggi atas materi yang telah dilaksanakan.
\end{abstract}

Kata kunci: teknologi informasi, digital, teknik informatika, android, matlab

\section{PENDAHULUAN}

Pelaksanaan kegiatan Pengabdian Kepada Masyarakat (PKM) yang dilaksanakan oleh Lembaga Perguruan Tinggi merupakan salah satu kegiatan yang bersifat pemberdayaan sebagai bentuk pengabdian kepada masyarakat guna menunjang pembangunan di segala aspek kehidupan. PKM juga merupakan salah satu bentuk pembelajaran dosen dan mahasiswa dilingkup masyarakat, dunia usaha dan instansi pemerintah/swasta sebagai bentuk aplikasi dan pembaruan kerangka teori yang telah diperoleh.

Kegiatan ini bisa dilakukan dengan memberikan pelatihan secara langsung kepada masyarakat. Pelatihan yang dilakukan dengan mengenalkan teknologi kepada masyarakat khususnya diberikan kepada siswa sekolah. Teknologi merupakan sesuatu yang penting bagi kehidupan para siswa di era digital sekarang ini. Secara umum, teknologi didefinisikan sebagai sebuah proses yang mentransformasikan bahan baku mentah atau modal intelektual menjadi sebuah produk ataupun jasa (Ivancevich, 2005). Teknologi telah digunakan di berbagai bidang seperti pertanian, kedokteran, pengelolaan informasi, pemasaran, atau lainnya. Sehingga, penguasaan terhadap teknologi menjadi suatu keniscayaan bagi setiap manusia, terlebih bagi masyarakat Indonesia. Tidak bisa dipungkiri, penguasaan terhadap teknologi setidaknya membutuhkan kemampuan-kemampuan dasar seseorang yang biasanya didapatkan melalui proses-proses pendidikan formal sebagaimana yang diamanatkan oleh negara dalam program wajib belajarnya. Hal tersebut berbeda dengan fakta yang menyatakan bahwa tingkat putus sekolah di level sekolah dasar masyarakat Indonesia cenderung masih tinggi (Pudjianto \& Syawie, 2015). Dengan tingginya angka putus sekolah tersebut akan berimbas pada tingkat kualitas manusia Indonesia yang rendah bila dibandingkan dengan beberapa negara lain (cnnindonesia.com, 2016). Oleh karena itu, akses-akses pendidikan di luar pendidikan formal masih sangat dibutuhkan dalam menunjang penguasaan teknologi-teknologi tersebut.

\section{METODE KEGIATAN}

Penggabungan komputer dengan teknologi dalam bidang telekomunikasi (khususnya internet) telah membawa manusia ke era informasi yang mengalir tanpa batas (Anita, 2010). Sehingga, pola-pola kehidupan lama bisa lebih dioptimalkan lagi dengan memanfaatkan teknologi yang biasa disebut 
sebagai teknologi informasi dan komunikasi (TIK) ini. Pengguna TIK sendiri bisa dikatakan sangat menyebar, mulai dari kalangan dewasa, remaja, bahkan anak-anak.

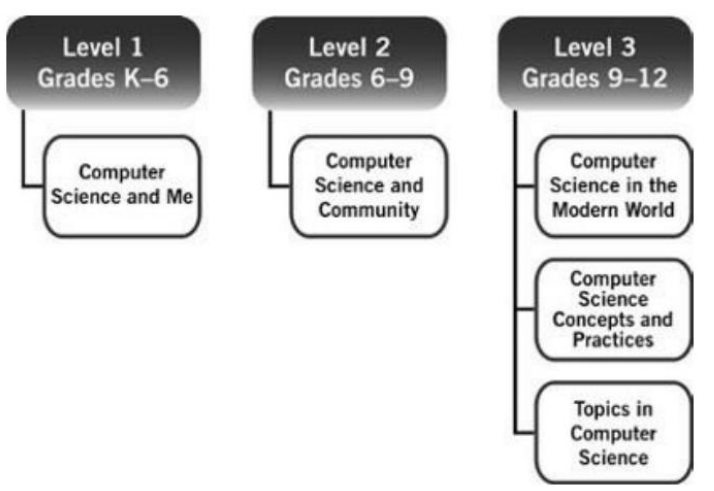

Gambar 1. Struktur Organisasi Standar Kurikulum Ilmu Komputer CSTA Untuk SD-SMA

Metode kegiatan yang kami lakukan yaitu dengan memberikan pelatihan secara langsung kepada siswa SMA dan SMK di wilayah Surabaya. Kegiatan pelatihan ini dengan cara mengundang tiga sekolah disekitar kampus Institut Teknologi Adhi Tama Surabaya (ITATS). Ketiga sekolah tersebut yaitu SMAN 20 Surabaya, SMKN 10 Surabaya, dan SMK Dr. Soetomo Surabaya. Langkah awal yang kami lakukan dengan melakukan survey untuk mengetahui bidang keahlian yang diajarkan di sekolah-sekolah tersebut. Kemudian pada prakteknya kita membagi siswa kedalam tiga kelompok pelatihan dan menerapakan TIK sesuai bidang.

Untuk dapat memanfaatkan TIK dengan baik dan benar, terdapat beberapa pengetahuan yang perlu dikenalkan kepada masyarakat yang biasa dikenal dengan istilah information technology literacy atau sering pula dikaitkan dengan information competency. Adapun pengetahuan-pengetahuan tersebut meliputi dasar-dasar TIK seperti pengetahuan dasar dunia digital, perangkat keras dan perangkat lunak komputer, teknologi informasi secara umum beserta teknik komunikasi datanya, dan hal-hal lain yang mendukung seperti potensi pemanfaatan, perundangundangan, keamanan (sekuritas), dampak negatif, serta etika dalam pemanfaatannya.

Sebagai bentuk penerapan TIK tersebut, kami mengadakan beberapa pelatihan dan penyuluhan. Diawal kegiatan kami mengumpulkan para siswa untuk dibekali dahulu dengan pengetahuan tentang teknologi informasi yang diberikan oleh para alumni ITATS. Setelah acara penyampaian materi dari alumni mengenai informasi dibidang teknik informatika dan sharing pengalaman bekerja dibidang teknik informatika, para siswa mengikuti pelatihan yang diadakan di laboratorium. Para siswa akan dibagi menjadi tiga kelompok sesuai bidang keahlian yang diajarkan di sekolah-sekolah untuk memperoleh pelatihan yang sesuai. Menurut Ganes, pada proses pelatihan ketertarikan peserta dalam mengikuti pelatihan dan pendampingan ditunjukkan dengan adanya media literasi yang baik. Peserta dapat mengikuti dan menerapkan tahapan mulai dari membuat, menggunakan dan mendemonstrasikan media literasi yang digunakan (Gunansyah, Rachmadiyanti, \& Subagiyo, 2018).

Mengingat materi dalam bidang teknik informatika sangat banyak (Rinaldi, 2003) dan pertimbangan agar proses pelatihan dapat disampaikan secara maksimal serta waktu yang terbatas maka materi yang diberikan dibagi tiap bidang pada labolatorium. Metode Pelatihan yang diberikan antara lain yaitu (1) pelatihan membuat game android, pelatihan ini dengan cara membuat game Android menggunakan Construct 2.0 kemudian dijalankan melalui browser. (2) pelatihan pengenalan Matlab yang digunakan untuk permasalahan komputasi algoritma. Para siswa juga diajarkan pengenalan cara pengolahan citra digital menggunakan Matlab. (3) pelatihan pengenalan jaringan dan simulasi packet tracer jaringan. Pada saat pelatihan berlangsung, para siswa diberikan kesempatan untuk bertanya dan menjawab selama pelatihan. Para siswa juga akan diberikan doorprize apabila dapat menjawab pertanyaan dari dosen yang memberikan pelatihan.

\section{HASIL \& PEMBAHASAN}

Kegiatan pengabdian kepada masyarakat yang dilakukan pertama dengan memberikan penyuluhan dan diberikan informasi mengenai teknologi informasi yang disampaikan oleh para alumni ITATS. Para siswa juga diberikan materi tentang sistem pendidikan di jurusan teknik informatika ITATS. 

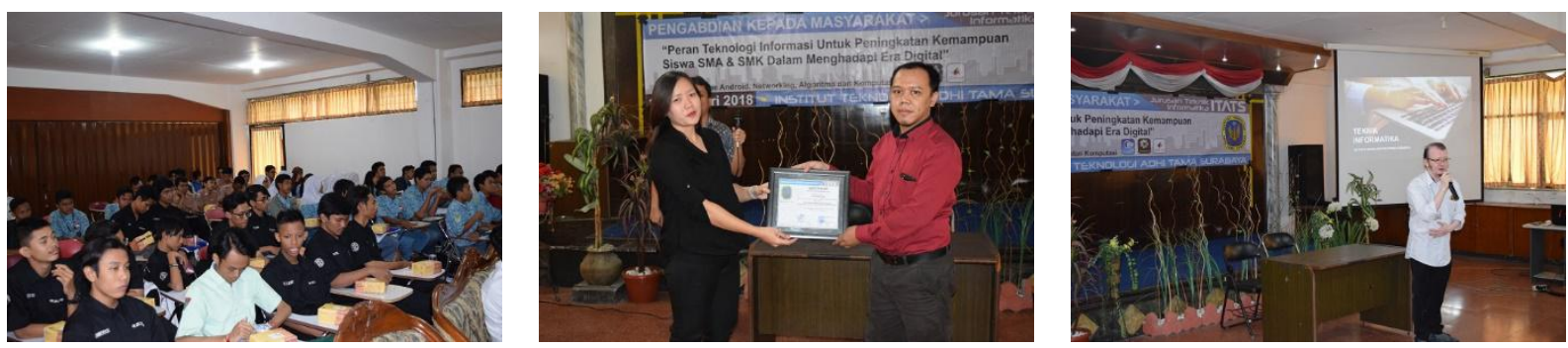

Gambar 2. Foto kegiatan pemberian materi dari alumni ITATS

Para alumni berbagi pengalaman yang diperoleh selama ditempat kerja. Pengalaman Antusiasme para siswa dalam mengikut kegiatan seperti ditunjukkan pada Gambar 2.

Berdasarkan sharing pengalaman dari alumni mahasiswa teknik informatika ITATS dan penyampaian materi tentang sistem pendidikan di jurusan teknik informatika, diketahui bahwa siswa SMA dan SMK masih kurang mengetahui ruang lingkup dari bidang teknologi informasi secara detail. Para siswa beranggapan jika teknik informatika hanya mempelajari komputer saja. Pada proses pembelajaran yang baik seharusnya berbasis dan berorientasi pada pengembangan materi yang memperhatikan dan menerapkan pembelajaran aktif, pelayanan terpadu dan kemampuan berpikir tingkat tinggi melalui proses pelatihan dan pendampingan.

Pada kegiatan pelatihan yang diselenggaran di 3 laboratorium jurusan teknik informatika, masing-masing memiliki materi tersendiri. Pelatihan pertama yaitu pelatihan game Android dengan menggunakan aplikasi Construct 2.0 diberikan dilaboratorium pemrograman. Pelatihan ini bertujuan untuk mengenalkan cara pembuatan game kepada siswa SMA dan SMK agar siswa dapat memahami proses pembuatan game yang biasa mereka mainkan. Antusias siswa dalam kegiatan pelatihaan game Android seperti ditunjukkan pada Gambar 3.



Pelatihan kedua yaotu pelatihan pengenalan Matlab untuk menyelesaikan permasalahan komputasi algortima diselenggarakan di laboratorium rekayasa perangkat lunak. Kegiatan ini memperagakan secara langsung penggunaan aplikasi Matlab dalam menyelesaikan berbagia macam permasalahan komputasi seperti pengolahan citra digital. Siswa SMA dan SMK secara langsung bisa mempraktekkan dan mencoba materi yang diberikan langsung sehingga siswa lebih memahami tentang permasalahan komputasi algoritma. Antusias siswa dalam mengikuti pelatihan aplikasi Matlab ditunjukkan seperti pada Gambar 4.

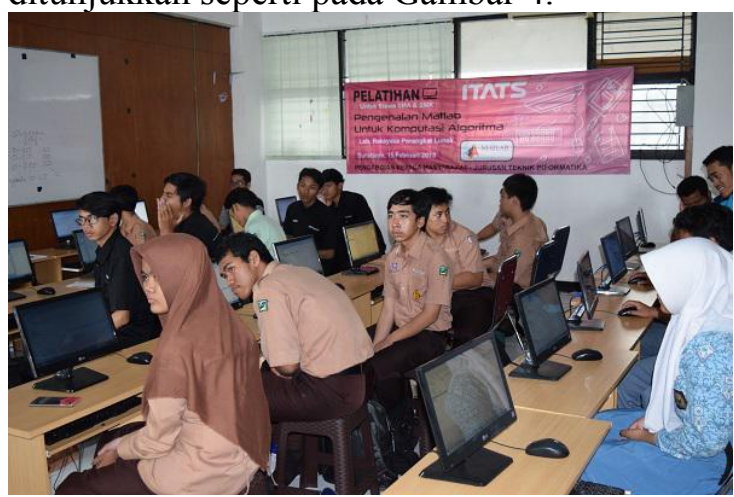

Gambar 4. Pelatihan Pengenalan Matlab Untuk Komputasi Algoritma

Kegiatan pelatihan ketida yaitu pelatihan jaringan dengan menggunakan simulasi packet tracer dilakukan di laboratorium jaringan. Pelatihan ini dengan menunjukkan simulasi tentang jaringan komputer dengan aplikasi packet tracer. Pelatihan ini bertujuan agar siswa SMA dan SMK memahami proses komunikasi dalam dunia internet. Antusias siswa dalam mengikuti pelatihan ditunjukkan seperti pada Gambar 5.

Gambar 3. Pelatihan Pembuatan Game Android 


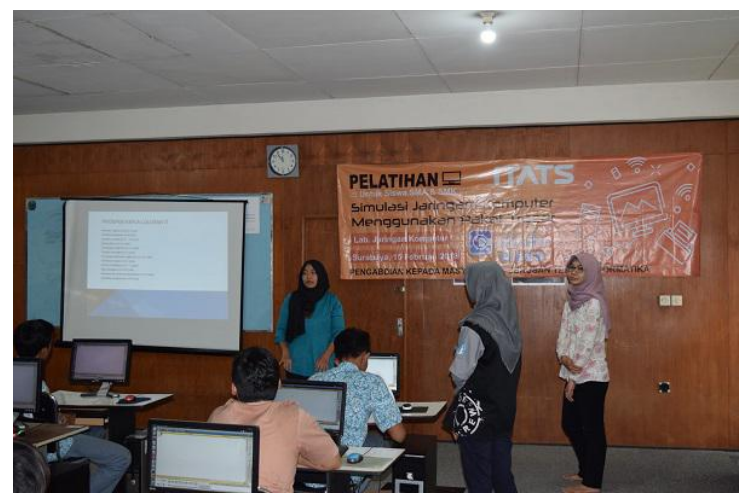

Gambar 5. Pelatihan Jaringan Menggunakan Simulasi Packet Tracer tentang analisis kebutuhan siswa SMA dan SMK terhadap teknologi informasi sebaiknya disesuikan dengan karakteristik pengguna (user) peserta pelatihan. Penggunaan media informasi dalam penyampaian materi sangat berperan dalam kelancaran proses pelatihan, bahan pelatihan, materi presentasi, literasi dan sumber bacaan baik online maupun offline juga harus disiapkan dengan baik.

Diakhir kegiatan dilakukan acara ramah tamah dan foto bersama dosen, guru pembimbing dan para siswa SMA SMK.

Berdasarkan pelatihan yang telah dilakukan telah dicapai beberapa hasil yaitu
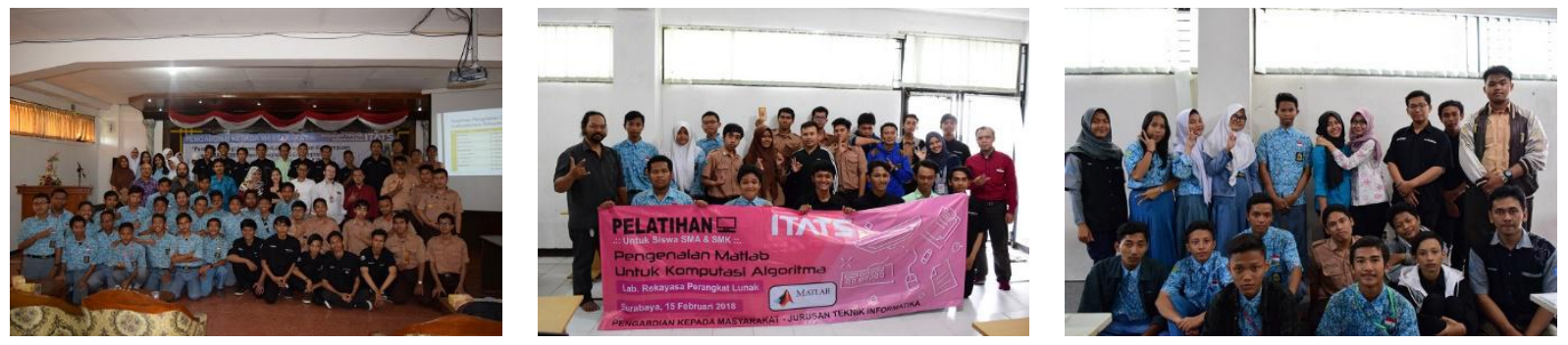

Gambar 6. Foto bersama

Evaluasi dilakukan setelah kegiatan pengabdian kepada masyarakat selesai diselenggarakan. Indikator keberhasilan dilihat dari kepuasan peserta yaitu siswa SMA dan SMK terhapat materi yang diberikan baik selama penyampaian materi dari alumni maupun selama pelatihan berlangsung. Hal tersebut disampaikan pada saat penutupan kegiatan. Tidak ada keluhan yang berarti, baik mengenai fasilitas maupun penyampaian materi, bahkan beberapa guru pembimbing mengusulkan beberapa tema untuk kegiatan pengabdian kepada masyarakat berikutnya yang sesuai dengan kebutuhan para guru di sekolah.

\section{KESIMPULAN \& SARAN}

Berdasarkan pelaksanaan kegiatan pengabdian masyarakat oleh teknik informatika ITATS, yaitu peran teknologi informasi untuk peningkatan kemampuan siswa SMA dan SMK dalam menghadapi perkembangan era digital dapat diuraikan beberapa kesimpulan. (1) pada era digital saat ini telah terjadi perubahan paradigma dalam dunia pendidikan, terdapat tantangan yang menuntut adanya perubahan pandangan terhadap cara belajar itu sendiri dan kemajuan teknologi informasi dan komunikasi yang memberikan banyak kemudahan dalam proses pembelajaran. (2) kegiatan pelatihan yang diselenggaran oleh jurusan teknik informatika ITATS berlangsung dengan lancar dan baik serta mampu memberikan pengetahuan kepada siswa SMA dan SMK.

\section{DAFTAR PUSTAKA}

Anita, S. (2010). Kemajuan Teknologi Informasi dan Komunikasi dalam Industri Media di Indonesia. GEMA EKSOS, 5(2). Retrieved March 30, 2018

cnnindonesia.com. (2016). Tingginya Angka Putus Sekolah di Indonesia. CNN Indonesia. Retrieved February 2, 2018, from

https://student.cnnindonesia.com/eduk asi/20170417145047-445-

208082/tingginya-angka-putussekolah-di-indonesia/

Gunansyah, G., Rachmadiyanti, P., \& Subagiyo, F. M. (2018). Keterampilan Informasi Melalui Pembuatan Media Literasi. Publikasi Pendidikan, 8(1), $13-18$.

Ivancevich, J. (2005). Perilaku dan Manajemen Organisasi. Jakarta: Erlangga. 
Pudjianto, B., \& Syawie, M. (2015). Kemiskinan Dan Pembangunan Manusiapoverty And Human Development. Sosio Informa, 1(3).

Rinaldi, M. (2003). Algoritma dan pemrograman dalam bahasa Pascal dan $C$. Bandung : Informatika. 